\title{
Dinâmicas sociogeográficas e políticas na Área Metropolitana de Lisboa em tempos de crise e de austeridade
}

\author{
Socio-geographical and political dynamics in the Metropolitan \\ Area of Lisbon in times of crisis and austerity
}

\author{
João Seixas \\ Simone Tulumello \\ Susana Corvelo \\ Ana Drago
}

\section{Resumo}

Este artigo, reconhecendo a relevância das dimen-

\section{Abstract}

sões territoriais e urbanas para uma melhor interpretação da atual crise e seus principais impulsionadores, bem como das suas consequências e reacções sociopolíticas, analisa a evolução recente da Área Metropolitana de Lisboa, perante tempos de crise económica e de políticas de austeridade. 0 artigo propõe duas conclusões, a merecer estudo adicional com o objectivo de uma sua possível teorização mais alargada: 1) podem distinguir-se fases distintas da crise e uma correlação entre estas, as políticas de austeridade implementadas e a correspondente ampliação dos efeitos da crise nos tecidos socioeconómicos territoriais; 2) verifica-se o aumento de um confronto de natureza estruturante entre políticas top-down de escalas europeia e nacionais e as dinâmicas sociopolíticas de escalas mais locais e mesmo bottom-up, redesenhando-se os quadros geopolíticos territoriais por formas crescentemente distintas e mais complexas; de divergências, aproximações e intersecções de base multi-escalar.

Palavras-chave: crise económica; austeridade; geografia da crise; Europa; Portugal.

This article, acknowledging the relevance of urban and territorial dimensions for the understanding of the current crisis and its main drives, as well as its effects and socio-political reactions, analyses the recent evolution of the Metropolitan Area of Lisbon in times of economic crisis and austerity policies. The conclusions, grounded on the case of Lisbon but deserving further theoretical building and comparative exploration, highlight: 1) the existence of different phases of the crisis and a correlation among these phases, the austerity policies that have been implemented, and the expansion of the crisis effects to the socioeconomic fabrics at the territorial scale; 2) a growing confrontation between top-down policies and bottom-up socio-political dynamics, that is, an increasingly complex and peculiar geopolitical framework made of multi-scalar divergences, convergences and intersections.

Keywords: economic crisis; austerity; crisis geography; Europe; Portugal. 


\section{Introdução}

Os últimos anos têm sido particularmente dolorosos para os territórios e sociedades do sul da Europa, devido à conjugação de uma forte crise financeira com as consequentes reações políticas por parte da União Europeia (UE) e dos estados-membros. A principal reação político-econômica tem sido, como se sabe, a implementação de um conjunto de medidas de austeridade, que têm provocado sérias disrupções quer nos tecidos sociais, econômicos e territoriais, quer nos próprios fundamentos de sociedades que se pretendem mais inclusivas e sustentáveis. Evidencia-se assim, de forma crescente, que a crise já não é - se alguma vez o terá sido - resultante dos universos público e estritamente financeiro, tendo antes razões de base bem mais estruturantes e multidimensionais.

Neste contexto, as mudanças sociopolíticas e as pressões resultantes da crise são especialmente evidentes nos territórios das metrópoles europeias. Uma dimensão relevante da formação da crise europeia resulta da queda do anterior paradigma de base econômica, suportado por um modelo expansivo de crédito de risco e ligado à urbanização, a produção e o consumo no espaço - crédito financeiro, territorial e ambiental - gerido em mercados financeiros crescentemente desregulados (Seixas, 2013). Em simultâneo, e diante das tendências de fractalização socioeconômica, os tecidos sociais urbanos foram testemunhando o desenvolvimento de novas culturas políticas e cívicas (id.). A própria Comissão Europeia advoga que as cidades irão reforçar seu papel de agentes centrais para a transição de paradigmas (CEC, 2011) pela sua natureza de espaços de conectividade, cidadania, criatividade e inovação. No entanto, a Comissão reconhecia igualmente que "o modelo europeu de desenvolvimento urbano sustentável se encontra ameaçado" (CEC, 2011, p. 14; tradução nossa): o que sucede não somente devido às turbulências emanadas da crise, mas também das respostas políticas e financeiras decorrentes desta. Esta é uma ameaça que coloca novos tipos de pressão sobre os sistemas urbanos e, em particular, desenha uma crescente polarização socioespacial, quer em termos de rendimento, quer no acesso às funções urbanas essenciais. Por outro lado, vai limitando a possibilidade de desenvolvimento sustentado de novos modelos de progresso social e econômico, em paralelo com a necessidade de uma ampla regeneração de base ecológica. $E$, se tal é relevante no panorama europeu mais amplo, a história e o posicionamento dos territórios urbanos do Mediterrâneo colocam o seu papel contemporâneo como particularmente significativo (Seixas e Albet, 2012).

As dimensões territoriais (e particularmente os territórios urbanos), embora estejam consideravelmente ausentes do coração dos principais debates políticos e acadêmicos, entendem-se aqui como essenciais para uma melhor interpretação da crise europeia atual, das suas próprias origens bem como das suas consequências sociais e políticas. Muito em particular nas regiões urbanas do Sul da Europa, territórios onde justamente os impactos da crise têm sido mais evidentes (Hadjimichalis, 2011; Werner, 2013; Cotella et al., 2016). Nesta linha de pensamento, este artigo traça uma análise dos impactos de cariz urbana da crise econômica e sua consequente gestão política as medidas de austeridade aplicadas sobre as 
respectivas sociedades e territórios -, desenvolvendo seu enfoque sobre a principal região urbana portuguesa, a Área Metropolitana de Lisboa (AML).

A hipótese central aqui colocada é a de que as tendências urbanas que emergiram no contexto da crise necessitam de ser lidas a partir de três dimensões distintas. Em primeiro lugar, os modos como os impactos espaciais da recessão econômica se encontram a reestruturar os padrões de inclusão e de exclusão nos sistemas urbanos. Em segundo lugar, a forma como as políticas econômicas de austeridade estarão a alterar ou a expandir tais padrões; e por sua vez como estas mesmas políticas estarão a alterar as próprias capacidades e prioridades de governação nas escalas urbanas metropolitana e local. Em terceiro lugar, olhar o modo como as dimensões política e cívica da cidade se encontram a reagir e a reconfigurar este panorama, alterando por sua vez os sistemas políticos urbanos, possivelmente de forma duradoura. Lisboa é aqui analisada em torno destas dimensões, e ainda como exemplo ilustrativo do surgimento de uma nova cultura política cujas características são particularmente complexas e eventualmente contraditórias. ${ }^{1}$

0 texto encontra-se estruturado em cinco seções. Na seção 2, desenvolve-se uma perspectiva crítica sobre a crise e as medidas de austeridade aplicadas, numa análise complementada por interpretações de bases geográficas e longitudinais. A seção 3 analisa o contexto das respostas políticas para a crise em Portugal, fornecendo o quadro das pressões de escala nacional e europeia, orientadas para a austeridade. A seção 4 expõe determinados dados que servem de base à exploração da natureza dos vários tipos de impactos e de sua distribuição espacial na AML. Na seção 5, é desenvolvida uma análise crítica dos principais fatores de mudança aos níveis institucional, político e cívico. As reflexões finais são desenvolvidas na seção 6 .

\section{Uma perspetiva critica sobre a crise europeia}

Nos discursos político-institucionais, as origens e a persistência da crise dos países do Sul da Europa são explicadas como a consequência de décadas de despesas públicas excessivas e até irresponsáveis, nomeadamente devido a sistemas de Estado Social supostamente insustentáveis (Blyth, 2013). É no predomínio dessas perspetivas que as políticas econômicas da austeridade, entendidas como necessárias para a re-consolidação dos orçamentos nacionais, e criar as condições para a recuperação econômica e competitiva, encontram sua fundamentação (Krugman, 2012).

Contudo, de acordo com Blyth (2013), a crise atual não é uma crise do setor público, mas antes uma crise do setor privado, a ser parcialmente paga com fundos públicos. Nesta perspetiva, as crises das dívidas soberanas são sobretudo resultado da utilização de fundos públicos para resgatar as instituições e 0 sistema financeiro europeu. Antes da crise, as dívidas soberanas de Espanha ou Irlanda encontravam-se abaixo de limiares críticos - em 2007, 26\% e $12 \%$ respectivamente do Produto Interior Bruto (PIB) (Blyth, 2013). Outros países como Itália, Grécia e Portugal detinham dívidas historicamente altas, embora essas não fossem consideradas um grande problema à escala 
europeia - e cresceram exponencialmente depois do início da crise. Tais dívidas não são então suficientes para explicar a crise dos países do Sul da Europa e da Irlanda. As razões devem ser procuradas, por um lado, no rebentar das bolhas da especulação imobiliária e financeira e, por outro lado, pela conjugação de tendências socioeconômicas recentes como a estagnação do crescimento desde 0 ano 2000, 0 envelhecimento das populações europeias e alguma incapacidade de mudanças de natureza estrutural nas dimensões político-institucionais.

Nos meses que se seguiram ao colapso de Wall Street de 2008, à implosão de alguns bancos, antes considerados demasiados grandes para ir à falência (too big to fail), e à revelação pública de práticas fraudulentas nos mercados financeiros, as análises dominantes apontavam para uma perigosa insustentabilidade do sistema financeiro vigente. Duas recomendações eram dadas aos governos nacionais: intervir nas instituições bancárias em risco, com o objetivo de tranquilizar os mercados e antecipar o pânico público, e lançar grandes programas de investimento público, com 0 objetivo de estimular uma rápida recuperação econômica. No final de 2008, a União Europeia aprova um ambicioso plano de recuperação (CEC, 2008) que previa 170.000 milhões de euros de investimentos pelos Estados Membros. Todavia, poucos meses depois, esgotavam-se os debates sobre a necessidade de regulamentar os mercados, enquanto as instituições internacionais, bem como governos e think-thank de natureza eminentemente conservadora, defendiam a necessidade da implementação de políticas de austeridade (Peck, 2013). A austeridade é "uma forma de deflação voluntária, na qual a economia se ajusta através da redução de salários, de preços e da despesa pública, com o objetivo de recuperar competitividade, o que é (supostamente) conseguido da melhor forma através de cortes nos orçamentos, nas dívidas e nos deficits do Estado. Assim, defendem os seus patrocinadores, inspira-se confiança nos mercados" (Blyth, 2013, p. 2; tradução nossa).

No entanto, enquanto os consequentes cortes no Estado Social e as pressões fiscais no mercado laboral têm aumentado as desigualdades e a pobreza, essas políticas não têm resultado em qualquer redução estruturante das dívidas nacionais, nem têm conseguido aliviar os estados de recessão nem estimulado o crescimento econômico (Krugman, 2012). Roitman (2014) estuda as narrativas sobre o risco de "colapso" dos sistemas político e econômico e seu papel na justificação da austeridade. Se entendermos a crise atual como uma crise da própria economia neoliberal - e de sua financeirização -, a austeridade pode ser entendida como o instrumento através do qual o neoliberalismo sobreviveu à sua própria crise: "o que podia ser descuidadamente definido como 'o sistema' foi descaradamente reiniciado com o mesmo software ideológico e administrativo, até com os mesmos bugs, que estiveram na origem do colapso" (Peck, 2013, p. 135; tradução nossa). É assim necessário entender a narrativa neoliberal para compreender e enquadrar a crise europeia. De acordo com Harvey (2005), o neoliberalismo é um projeto de reestruturação do capitalismo e de restauração das condições para acumulação de capital. As especificidades das dinâmicas neoliberais mostram como 0 Estado não tem sido reduzido, como defendem as concepções liberais tradicionais, mas antes reorganizado para permitir formas específicas de competição (Wacquant, 2012), através de 
uma mistura contraditória de regulação e desregulamentação (Brenner et al., 2010; Rodrigues e Teles, 2011). Os mercados (financeiros) são desregulados e, ao mesmo tempo, os Estados-nação intervêm no espaço financeiro e econômico com o objetivo de favorecer a acumulação de capital, através da privatização de serviços públicos e de novas formas de parcerias público-privadas em matérias públicas de base concessionável, consideravelmente garantidas.

Uma leitura crítica sobre as dinâmicas neoliberais é portanto necessária para compreender a enorme relevância da crise e da austeridade nas cidades, por duas razões. Em primeiro lugar, o papel da produção urbana e da reestruturação territorial têm sido centrais ao desenvolvimento e ao sucesso das abordagens neoclássicas e neoliberais desde pelo menos os anos 1980 (Brenner, 2004). As fortes dinâmicas de produção - e de consumo - de territórios urbanos, suburbanos e peri-urbanos podem ser entendidas como resultados ou mesmo estratégias coerentes e estruturantes de acumulação (Peck et al., 2013). Embora exista uma significativa variedade de tendências locais e regionais, principalmente relacionadas com a variedade dos contextos institucionais, político-culturais e de governança, e que justificou numerosas críticas sobre a utilidade do neoliberalismo como conceito teórico para uma generalização tendencial (Baptista, 2013), podem contudo ser distinguidas algumas tendências comuns - embora não exclusivas - na governança urbana nessas ópticas, em torno de conceitos como competitividade territorial, marketing urbano, parcerias público-privadas, subcontratação, concessão, privatização (Sager, 2011).

Em segundo lugar, muitos consideram a crise econômica - e especialmente a crise no
Sul da Europa - como o culminar de trajetos de longo prazo de desenvolvimento desigual promovido justamente pelas políticas neoliberais (Hadjimichalis, 2011; Blyth, 2013). Tal visão pode ser exemplificada através das políticas da habitação e da passagem de uma política de provisão pública de habitação social para uma outra de apoio à propriedade privada (o right to buy dos tempos de Margaret Thatcher). Essa passagem, em conjugação com uma paulatina erosão das capacidades do Estado Social, "forçou as pessoas nos Estados Unidos e em outros países a confiar sempre mais na propriedade da casa como substituto dos mecanismos sociais de partilha de riscos. Os esforços individuais para substituir recursos e serviços públicos pela condição de proprietário da habitação empurraram os preços para níveis claramente insustentáveis" (Schwartz, 2012, p. 53; tradução nossa). As bolhas do imobiliário habitacional e da dívida privada que resultaram permitiram assim elevadas performances especulativas e estiveram na origem do colapso financeiro (Blyth, 2013).

É aliás possível notar como as categorias principais adotadas para uma economia em tempos de crise são praticamente as mesmas do período anterior a 2008, nomeadamente a ênfase na necessidade de atrair investimentos e os discursos sobre competição global, promovidos pelas organizações internacionais (Oosterlynck e González, 2013). Produção e consumo na economia global não se encontram unicamente concentrados nos espaços urbanos, mas as agendas políticas dominantes reconhecem a cidade como um elemento nodal na criação de fontes de consumo. Nomeadamente em âmbitos de projetos de renovação e de requalificação urbana de base 
competitiva, em projetos de marketing urbano e de fomento turístico, nos incentivos públicos ao contínuo fomento da propriedade privada, nas tendências de comercialização ou mesmo de semiprivatização de espaços públicos e ainda no papel-chave das instituições financeiras nos novos regimes urbanos (Peck et al., 2013). Nesse sentido, pode-se avançar que uma interpretação da natureza da atual crise necessitará também de uma análise crítica das dinâmicas das instituições e dos regimes de governo urbano e territorial.

\section{Questões de contexto: a agenda da austeridade e seus impactos em Portugal}

A deflagração da crise financeira em 2008 marcou o início de uma época de profundas mudanças na sociedade e na política portuguesa. É possível encontrar abordagens variadas e até contraditórias nas respostas políticas à crise, organizadas segundo fases temporalmente consecutivas (cf. Pedroso, 2014): num primeiro momento, as políticas para a sustentação do 'sistema' e para o relançamento da economia; num segundo momento, o início da implementação de políticas de austeridade sobretudo nos setores financeiros e fiscais; por fim, a implementação da austeridade numa lógica já claramente ideológica e em larga escala. ${ }^{2}$

Em linha com as primeiras reações à crise pelas instituições europeias (cf. a seção anterior), o governo português emitiu um conjunto de garantias públicas relativas às dívidas do setor bancário privado e assumiu o controle de alguns bancos de investimento, cujas atividades de endividamento e especulação de risco se tornaram públicas. Simultaneamente, foi apresentada uma agenda aparentemente neo-Keynesiana para o orçamento de 2009: ${ }^{3}$ os trabalhadores públicos receberam um aumento salarial de $2,9 \%$ e foi lançado um programa ambicioso de obras públicas, principalmente relativo a infraestruturas de transportes. Mas, já em 2010, as tendências foram revertidas: 0 investimento em obras públicas foi congelado, as receitas fiscais encolheram e a despesa pública em subsídios de desemprego aumentou. Ao mesmo tempo que a crise europeia se desenrolava, as taxas de juro sobre a dívida pública disparavam e o deficit crescia de forma considerável. Portugal encontrava-se oficialmente em crise de dívida soberana.

A primeira série de políticas de ajustamento fiscal seria entretanto implementada em 2010/11: os impostos foram aumentados, as reformas e os salários públicos foram congelados e uma nova legislação veio limitar o acesso aos apoios sociais. Em abril de 2011, após o chumbo parlamentar de um novo pacote de 'ajustamento', o Primeiro-Ministro socialista solicitaria ajuda internacional. A Troika que realizou o empréstimo a Portugal (Fundo Monetário Internacional, Comissão Europeia e Banco Central Europeu) impôs à política nacional um programa especialmente severo nas vertentes orçamental e político-administrativa - tal como havia imposto na Grécia e na Irlanda, e mais tarde, se bem que de forma algo mitigada, na Espanha. Dois meses depois, um governo de centro-direita tomaria posse. As políticas de austeridade aplicadas em larga escala enquadraram-se assim na permissão de uma assistência financeira de base institucional, sendo justificadas por sobre uma narrativa da 
incapacidade portuguesa na restauração própria das estruturas públicas e administrativas e da sua economia.

Esse diagnóstico seria construído a partir de uma representação reconhecidamente distorcida dos padrões de despesa pública e privada que, supostamente, haviam conduzido a um endividamento nacional insustentável. Contudo, esta visão consegue ser facilmente posta em causa através uma análise mais detalhada às contas da dívida nacional (Abreu et al., 2013). A dívida pública portuguesa crescera gradualmente desde meados dos anos 1990, chegando à média da UE por volta do 2005. A maior componente de endividamento seria desenvolvida só após 2008, em importante medida como resultado da crise financeira internacional. Ao mesmo tempo, o endividamento das famílias permanecera relativamente limitado: em 2010, cerca de $63 \%$ da população não tinha qualquer dívida de crédito - não obstante cerca de $80 \%$ das dívidas existentes serem relativas a empréstimos para habitação. $\mathrm{E}$, apesar da crise econômica, em 2013 apenas 6,6\% dos empréstimos reportavam a casos concretos de incumprimento. No endividamento para habitação, o incumprimento era mesmo assim mais baixo, embora esse tenha vindo a aumentar, passando de 1,8\% em 2008 para 2,9\% em 2012 (Santos e Costa, 2013). Como será de esperar, nas áreas urbanas, o incumprimento no crédito à habitação é superior à média nacional: na metrópole de Lisboa tem atingindo no final de 2014 o rácio de 3,7\%, com alguns municípios a atingirem 6,3\%. ${ }^{4}$

Desde o início do novo milênio, Portugal sofre uma sequência de choques econômicos significativos com elevado impacto na sua capacidade de competitividade internacional: a adoção de uma moeda forte (o euro, em 2002), os impactos da liberalização do comércio mundial e sobretudo das exportações chinesas nos mercados tradicionais de exportação portuguesa, a crise petrolífera de meados dos 2000. 0 resultado tem sido intitulado como a 'década perdida' (comumente assim referida nos media) da economia portuguesa. Entre 2000 e 2010, o PIB português cresceu a uma taxa média anual de cerca de 1\%. De acordo com Reis e Rodrigues (2011), as razões dessas dificuldades podem ser encontradas nos tipos de respostas políticas aos choques exteriores, que conduziram a um modelo econômico crescentemente norteado por baixos salários e uma crescente desigualdade, em lugar de um redirecionamento de investimentos em setores com maior valor acrescentado econômico, mas também social e ambiental.

Sem ter em consideração qualquer tipo dessas perspectivas, as terapias de política econômica e pública da Troika consistiriam sobretudo na materialização de cortes drásticos na despesa e no investimento público, bem como no relançamento de políticas de reestruturação e de neo-liberalização em múltiplos setores. $A$ administração, os serviços e os salários públicos foram repetidamente reduzidos, a despesa pública em saúde e educação consideravelmente reduzida, um programa de demissão de trabalhadores públicos apontaria para uma redução de cerca de 50.000 postos de trabalho. Também as políticas de apoio social tais como as políticas contra a pobreza e de redução de desigualdades, assim como os subsídios de desemprego, seriam cortados. Aumentaria a carga fiscal - incluindo de bases extraordinária - por sobre as reformas, os salários e o consumo. Enfim, um vasto programa de privatização em 
setores econômicos estratégicos (tais como os transportes públicos, a energia, as comunicações, os correios, os aeroportos e a companhia área nacional) seria implementado.

Os efeitos econômicos sociais e ainda econômicos do 'programa de ajustamento' imposto pela Troika desde 2011 são hoje muito evidentes (Abreu et al., 2013): entre 2011 e 2013, o PIB português cairia 5,9\% - surgindo algum sinal de crescimento somente no ano 2014, com apenas $+0,9 \%$. Em 2013, o consumo privado regressaria aos níveis do ano de 2000, e o consumo público aos níveis do ano de 2002, não havendo memória (i.e. não há comparação nos dados estatísticos disponíveis) de um colapso como o que foi verificado nas taxas de investimento público e privado. No primeiro trimestre de 2013, o investimento líquido na economia portuguesa era menor em $20 \%$ do que o do ano de 1995. Entre 2011 e 2013, o rendimento nacional bruto diminuíra $4 \%$, enquanto o rendimento de trabalho tivera uma redução de $9,7 \% .{ }^{5}$ Esses dados podem ser interpretados como uma acentuada pressão para a contração salarial, típica das economias em recessão, mas são sobretudo resultado das políticas de austeridade implementadas.

A próxima seção do artigo focalizar-se-á na análise empírica da Área Metropolitana de Lisboa, para esse conturbado período. As tendências econômicas, territoriais e sociodemográficas da maior metrópole portuguesa serão apresentadas por forma a interpretar os efeitos da crise econômica e das correspondentes respostas políticas através de análise dos dados correspondentes.

\section{Área Metropolitana de Lisboa: a crise em movimento ${ }^{6}$}

\section{Desempenho econômico e efeitos territoriais}

Como capital de um país relativamente pequeno e tendencialmente macrocéfalo, Lisboa (com sua Área Metropolitana, a AML, Figura 1) sempre foi motor central para o desempenho global do país (Quadro 1). A concentração de população, de produção e de consumo tem atraído de forma permanente grande parte dos recursos nacionais bem como investimentos consideráveis em Investigação e Desenvolvimento. A AML reúne assim parte significativa dos recursos demográficos e produtivos nacionais: $27 \%$ dos habitantes, $26,2 \%$ do emprego, $37,3 \%$ do Valor Acrescentado Bruto.

Pelas mesmas razões, a AML foi fortemente afectada pela crise econômica bem como pelo conjunto de medidas de austeridade aplicadas pelo governo central. Não obstante, tomando em análise o Índice Sintético de Desenvolvimento Regional ${ }^{7}$ (Quadro 2), tal efeito surge evidenciado por formas aparentemente contraditórias, diante da trajectória dos valores referentes ao período anterior à implementação de medidas de austeridade, e respectivamente aos anos após o início da implementação de tais medidas (2010 em diante).

A componente 'competitividade' do índice revela um ligeiro padrão de melhoria até ao ano de 2010, em contradição com as componentes 'coesão' e 'qualidade ambiental', que 
Quadro 1 - Indicadores principais sobre a Área Metropolitana de Lisboa (AML)

\begin{tabular}{|l|c|c|}
\hline \multicolumn{1}{|c|}{2013} & Portugal & AML \\
\hline População (milhões) & 10,5 & 2,8 \\
PIB pc (PT=100) & 100 & 139 \\
VAB preços correntes (M€) & 150.465 & 56.154 \\
População Empregada dos 15 aos 64 anos (milhares) & 4.158 & 1.092 \\
Produtividade (milhares de euros) (2010) & 30,7 & 38,7 \\
\hline
\end{tabular}

Elaborado pelos autores. Dados: INE (censos); CCDR- LVT.

se degradam visivelmente. Uma análise mais cuidadosa permite compreender essa aparente contradição. Todas as variáveis que concorrem para a componente competitividade (PIB per capita, pessoal qualificado, crescimento das exportações, intensidade em I\&D ou a prevalência de atividades intensivas em conhecimento) não só apresentam na $A M L$ valores muito acima dos da média nacional, como reagem de forma menos imediata aos efeitos da crise por força do perfil de especialização da área metropolitana. Para além do mais, a efetiva dependência do comportamento da procura no mercado interno na região (em desaceleração) surge também atenuada na AML pelo perfil de exportações, dando assim uma sensação de crescimento, apesar de o real comportamento das variáveis macroeconômicas não se mostrar tão positivo.

Assim, durante a primeira fase da crise econômica (2007-2010) e antes da economia da região ter iniciado um registo de contração, verificou-se um crescimento moderado na $A M L$, devido sobretudo aos setores exportadores e a um crescimento ainda relativamente contido do desemprego (8,2\% em 2007; 9,8\% em 2009) - ambas essas variáveis com comportamentos melhores diante das médias nacionais. Além disso, a predominância na AML dos setores do turismo e dos serviços, terá contribuído para a sustentação dos depressores econômicos. Por seu lado, será durante a segunda fase (após 2010) que todos os componentes do índice apresentam relevantes reduções. 
Figura 1 - A Área Metropolitana de Lisboa (AML)
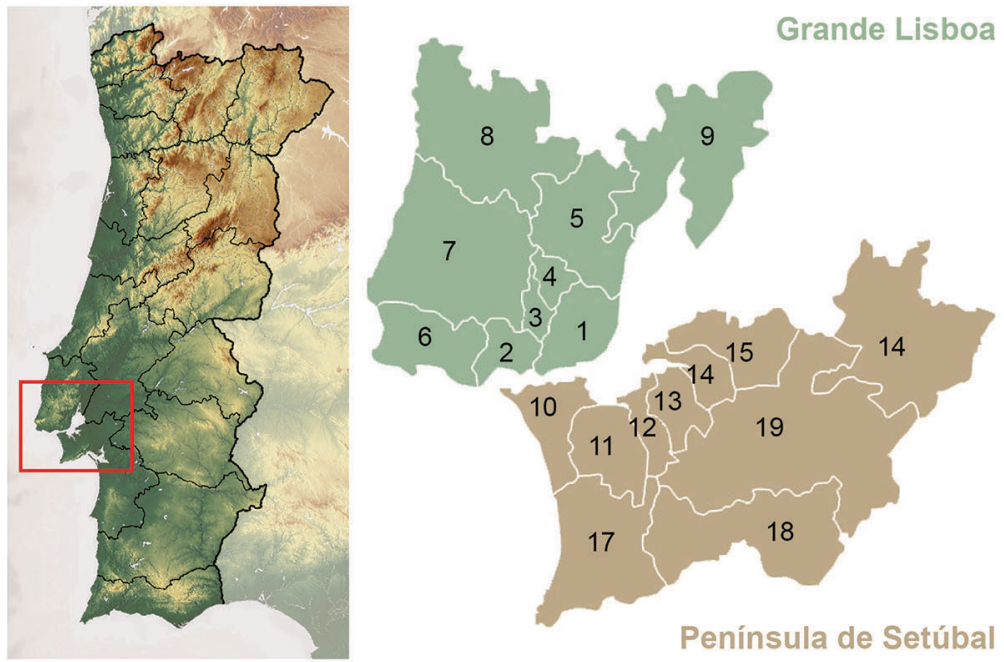

1. Lisboa

2. Oeiras

3. Amadora

4. Odivelas

5. Loures

6. Cascais

7. Sintra

8. Mafra

9. Vila Franca de Xira

10. Almada

11. Seixal

12. Barreiro

13. Moita

14. Montijo

15. Alcochete

16. Sesimbra

17. Setúbal

18. Palmela

Elaborado pelos autores. Mapa Portugal: Wikipedia.

Quadro 2 - Índice Sintético de Desenvolvimento Regional (Portugal)

\begin{tabular}{|c|c|c|c|c|c|}
\hline \multicolumn{2}{|c|}{ Portugal } & ISDR & Competitividade & Coesão & $\begin{array}{c}\text { Qualidade } \\
\text { ambiental }\end{array}$ \\
\cline { 3 - 6 } & & 100 & 100 & 100 & 100 \\
\hline \multirow{3}{*}{ AML } & 2011 & 105,33 & 113,26 & 103,99 & 98,01 \\
& 2010 & 106,48 & 113,93 & 104,64 & 100,20 \\
& 2008 & 106,79 & 113,18 & 106,57 & 100,00 \\
& 2006 & 107,21 & 113,01 & 107,78 & 100,27 \\
\hline
\end{tabular}

Elaborado pelos autores. Dados: INE.

A análise de outras variáveis de desempenho econômico complementa a compreensão dos efeitos reais da crise bem como dos efeitos gerados pelas medidas de austeridade entretanto aplicadas, notavelmente as quedas abruptas verificadas nos níveis de investimento privado e, especialmente, de investimento público, acompanhadas por cortes elevados nos gastos públicos para supostamente restaurar a competitividade econômica e a sustentabilidade financeira. A tendência observada quanto ao investimento é evidente nos números registrados da Formação Bruta de Capital Fixo, ${ }^{8}$ que cairão quase $20 \%$ entre 2008 e 2011. Cerca de 65 mil empresas (17,6\% do total) desaparecerão entre 2008 e 2012 na AML, passando sua taxa de sobrevivência a apresentar valores abaixo da própria média nacional. 
Os setores do imobiliário e da construção foram os primeiros a sofrer com a crise, como bem revela a queda do valor dos contratos de compra e venda imobiliária (Figura 2). A AML é um complexo sistema densamente urbanizado, como resultado de várias décadas de prevalência de produção sobre 0 espaço e do fomento das economias de urbanização: entre 2001 e 2011, e diante de um crescimento de $6 \%$ da população, dá-se um crescimento da área construída de cerca de $14,2 \%$. Por seu lado, e subdividindo essa década, verifica-se que após um crescimento sustentado no início dos anos 2000, as obras de construção nos dois grandes distritos da AML (Lisboa e Setúbal) caem para metade na segunda metade da década e início da seguinte (2007-2012).

Figura 2 - Construção e setor imobiliário na AML

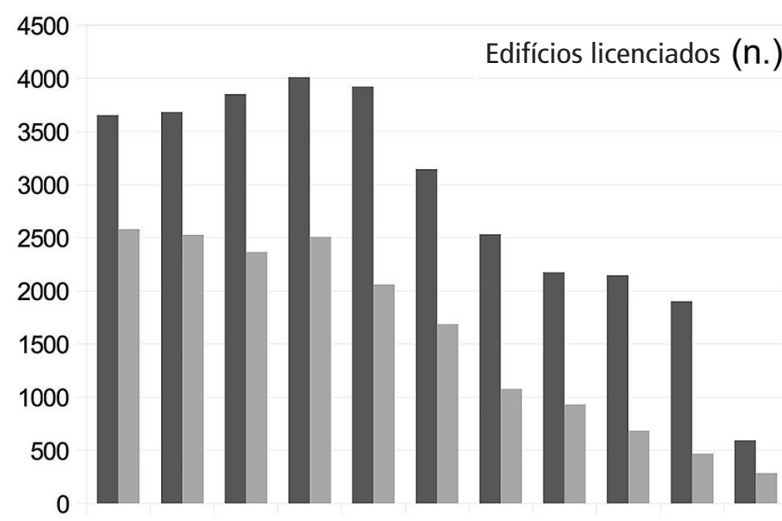

20032004200520062007200820092010201120122013
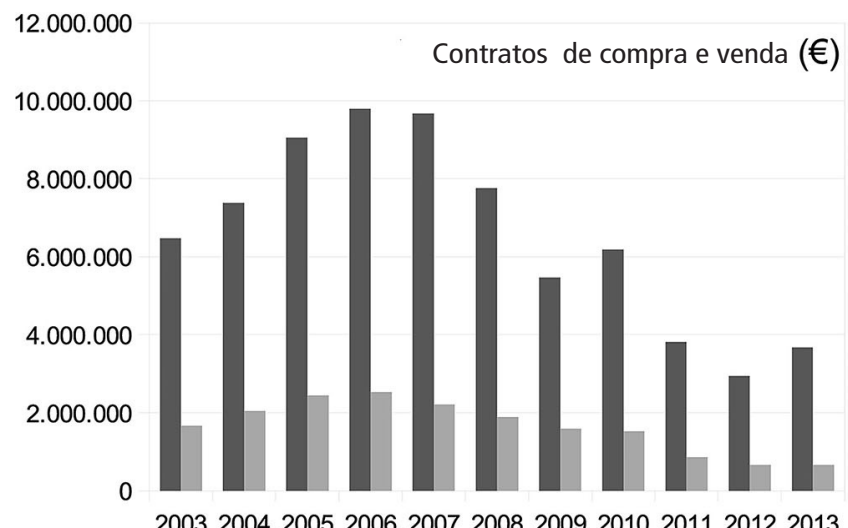

Elaborado pelos autores. Dados: INE. 
É ainda de salientar que a depressão financeira intervém num processo já em curso (Figura 2). 0 número de contratos de compra e venda no setor da construção pára de crescer em 2006 com o rebentar da bolha imobiliária, bem como com uma crescente eficácia na regulamentação do planejamento e ordenamento urbano, após décadas de urbanização pouco regulamentada (Fernandes e Chamusca, 2014). A contração do setor da construção reforçará uma polarização regional, especialmente no distrito de Setúbal, onde os "municípios com baixos níveis de escolaridade e de qualificação, com problemas estruturais de inclusão social e precariedade laboral e dependentes de segmentos de mercado de trabalho em retração (construção civil, serviços desqualificados) evidenciam uma maior sensibilidade imediata aos efeitos da crise" (Ferrão, 2013, p. 256).

Por sua vez, as insolvências de hipotecas bancárias irão aumentar quase $50 \%$ entre 2009 e 2013, revelando das crescentes dificuldades financeiras por parte das famílias. Com os discursos políticos a apontarem as famílias como co-responsáveis pela crise nacional, diante de seu nível de endividamento excessivo, o crescimento da dívida privada pode não obstante ser explicado, em principal medida, pela falta de uma política global de habitação durante décadas. Em 2010, os empréstimos à habitação eram responsáveis por cerca de $80 \%$ do endividamento das famílias, tendo a compra de casa própria sido incentivada por sucessivos governos, com benefícios fiscais e sistemas de crédito subsidiados pelo Estado para aquisição de habitação. Essas políticas iriam criar uma articulação e uma simbiose de caráter particular, ligando política pública, investimento das famílias, endividamento privado e instituições de crédito financeiro (Santos, 2013).

\section{Tendências sociodemográficas}

A AML é uma região europeia altamente qualificada. Detém as maiores universidades do país, bem como o maior número de centros de I\&D e um número muito considerável de empresas inovadoras - cerca de $62 \%$ das empresas apresenta atividades de inovação, diante de 54\% na média nacional (INE, 2014a). Apresenta ainda $16,8 \%$ de seus habitantes com grau de ensino superior (diante de uma média nacional de $11,8 \%$ ) e um ligeiro aumento de sua vitalidade demográfica, visível no aumento da proporção de jovens na população total (de 14,9\% em 2001 para 15,5\% em 2011, segundo os (ensos) e de uma população imigrante bastante jovem. Não deixa a área metropolitana, porém, de ser uma região muito envelhecida e com taxas de natalidade em relativo declínio, tendo ao longo dos últimos 10 anos a percentagem de pessoas 65 anos ou mais passado de $15,4 \%$ para $18,2 \%$ da população total. Essas tendências são ainda mais significativas quando entendidas a partir da perspectiva do mercado de trabalho e suas características intensificadas ao longo dos anos de crise. Na verdade, os efeitos duplos da crise e das respostas políticas são aqui igualmente muito claras, tendo-se assistido a uma redução em cerca de 180.000 trabalhadores da população empregada entre 2008 e 2013.

Concomitantemente, a taxa de desemprego mais do que duplicou neste período (de $8,2 \%$ para $18,5 \%$ ), tendo-se acentuado esse aumento desde o resgate financeiro e 
as imposições dos credores internacionais em 2011 (Figura 3), confirmando os efeitos depressores da austeridade. Em particular, a taxa de desemprego dos jovens aumentou de 18,6\% em 2007 para 45,3\% em 2013. Os desempregados inscritos nos serviços públicos de emprego (números atualizados mensalmente que permitem capturar as tendências de forma mais rápida) confirmam estes resultados: 0 desemprego registado na $\mathrm{AML}^{9}$ começou a subir, embora a um ritmo relativamente baixo, após 2008, aumentando porém de forma muito mais drástica a partir de 2010/11, quando os cortes no investimento e nas políticas sociais efetuadas pelo governo central se implementaram. Mais recentemente, tem-se verificado uma ligeira melhoria nesse indicador, devida em parte ao acentuar da desistência dos desempregados inscritos na procura de trabalho, e não tanto a uma efetiva retomada econômica.
Um dos resultados mais sérios registra-se no risco de pobreza, que tem vindo a aumentar de forma muito preocupante desde 2009 (Quadro 3), invertendo uma tendência positiva traçada desde o início da década e resultado de uma estratégia de políticas públicas de combate à pobreza. De acordo com as estatísticas da UE referentes ao Inquérito às Condições de Vida e Rendimento (INE, 2014b) em 2013, 19,5\% da população de Portugal encontrava-se em risco de pobreza, mesmo após transferências sociais, contra uma taxa de 17,9\% em 2009. A taxa de risco de pobreza para a população desempregada no país foi de 40,2\% em 2012, registando um aumento de quase quatro pontos em relação a 2009. Por seu lado, os novos aumentos das assimetrias na distribuição de rendimentos desde 2010 inverteram as tendências de redução das desigualdades econômicas da década anterior (Alves, 2014).

Figura 3 - Evolução do desemprego e dos beneficiários

do Rendimento Social de Inserção na AML
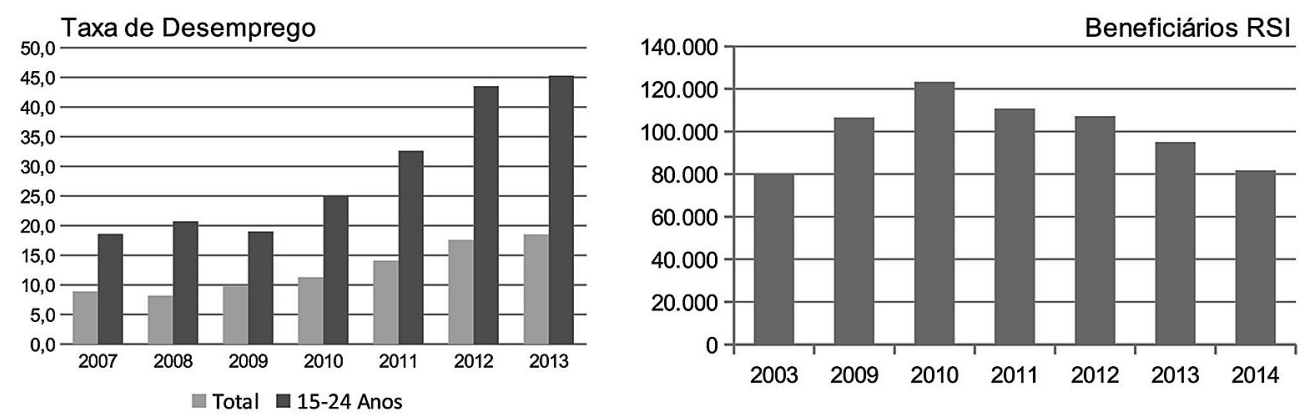

Elaborado pelos autores. Dados: INE e Pordata (http://www.pordata.pt/Home) 
Mesmo não detendo dados consistentes sobre a pobreza em um nível mais subnacional, existe conhecimento suficiente para se poder afirmar que as áreas urbanas foram profundamente afetadas nesses âmbitos. Na primeira fase da crise, registou-se um aumento significativo (de cerca de 66\%) no número de beneficiários do Rendimento Social de Inserção (RSI, uma prestação de segurança social para as famílias mais pobres) na AML. Desde 2010, no entanto, as medidas de austeridade e os cortes nas prestações de apoio social originaram uma redução drástica desses números, em contraste vivo e paradoxal com o crescimento do desemprego, da pobreza e das desigualdades (Figura 3, Quadro 3).

Além disso, as tendências de envelhecimento estruturantes na população da $A M L, 0$ correspondente aumento do número de beneficiários de pensões e o baixo valor das pensões médias no sistema de Segurança Social (CCDR-LVT, 2013) acentuaram a população mais idosa como um grupo social altamente vulnerável e com alto risco de pobreza. Os cortes acentuados no Complemento Solidário Para Idosos (um importante benefício social para a população idosa e mais pobre) que o governo central impôs desde 2011, aumentaram por sua vez a percentagem de população com mais de 65 anos de idade exposta à pobreza.

Existem ainda outras dimensões em que se tem verificado efeitos depressores decorrentes das medidas de austeridade, da redução do emprego, dos salários e do rendimento familiar. Relevante exemplo mostra ser a dimensão da mobilidade diante desta vasta e dispersa região urbanizada da $A M L$, caracterizada por deslocações diárias e semipolicêntricas muito significativas: a população da cidade central de Lisboa (cerca 600.000 habitantes) duplica ou mesmo quase triplica durante muitos dos dias úteis. Entre 2008 e 2010, o número de viagens urbanas e suburbanas no transporte público manteve-se estável, enquanto no período 2010-2014 verificou-se uma relevante queda de $28,5 \%$ no seu uso (AMTL, 2013; 2014). Assume-se que entre as razões principais estejam a perda de capacidade econômica e de poder de compra causada pela crise econômica, mas também os cortes na oferta pública de transporte metropolitano e o aumento significativo das tarifas de transporte público ( $24 \%$ no período 2010-2012), medidas decididas pelo governo central.

Finalmente, uma nota referente aos fluxos de emigração emergentes, sobretudo pelas suas potenciais consequências. Desde 2010 que se regista uma tendência de inversão completa das tendências migratórias na AML: os fluxos de imigração têm caído drasticamente (sendo os valores de 2012 metade dos de 2009), enquanto a emigração, especialmente entre os jovens, sobe abruptamente. Os dados estatísticos oficiais indicam que em 2012 o número de emigrantes triplicou em relação a 2009. Por seu lado, alguns estudos estimam que entre 2007 e 2012 terão saído do país cerca de 82,5 mil portugueses por ano, apontando os dados atuais para uma saída de 110 mil em 2013 (Observatório da Emigração, 2014). Em 2011, registrar-se-á pela primeira vez em décadas, um saldo demográfico global negativo. Estas tendências prefiguram assim um efeito que vai para além dos efeitos da crise e das políticas de austeridade: a perda de capital humano, por via de uma população cada vez mais envelhecida, mas especialmente por via da emigração de trabalhadores jovens, qualificados e instruídos. 
Quadro 3 - Indicadores de Portugal (EU-SILC 2012 e EU-SILC 2014) ${ }^{10}$

\begin{tabular}{|l|r|r|r|r|r|c|}
\hline \multicolumn{1}{|c|}{ Ano de referência } & \multicolumn{1}{|c|}{2009} & 2010 & \multicolumn{1}{c|}{2011} & 2012 & \multicolumn{1}{c|}{2013} & 2014 \\
\hline $\begin{array}{l}\text { Taxa de Risco de Pobreza antes de } \\
\text { Transferências Sociais (\%) }\end{array}$ & 43,4 & 42,5 & 45,4 & 46,9 & 47,8 & - \\
$\begin{array}{l}\text { Taxa de Risco de Pobreza após } \\
\text { Transferências Sociais (\%) }\end{array}$ & 17,9 & 18,0 & 17.9 & 18,7 & 19,5 & - \\
Privação Material Severa (\%) & 9,1 & 9,0 & 8,3 & 8,6 & 10,9 & $10,6(\mathrm{Po})$ \\
População em Risco de Pobreza (\%) & 24,9 & 25,3 & 24,4 & 25,3 & 27,5 & $27,5(\mathrm{Po})$ \\
\hline Coeficiente de Gini & 33,7 & 34,2 & 34,5 & 34,2 & 34,5 Po) & - \\
$\begin{array}{l}\text { Desigualdade na Distribuição de } \\
\text { Rendimento (S80/S20) }\end{array}$ & 5,6 & 5,7 & 5,8 & 6,0 & 6,2 (Po) & - \\
$\begin{array}{l}\text { Desigualdade na Distribuição de } \\
\text { Rendimento (S90/S10) }\end{array}$ & 9,2 & 9,4 & 10,0 & 10,7 & 11,1 Po) & - \\
\hline
\end{tabular}

Elaborado pelos autores. Dados INE (2012; 2014b). Po - valor provisório.

\section{Duas crises, mais uma}

A análise dos impactos provocados pela crise econômica na AML, acima expostos, mostram que podem ser identificadas três fases temporais distintas no âmbito das consequências que se seguiram ao colapso financeiro global. Na primeira fase (grosso modo, de 2008 a 2010), o crash financeiro afetou fortemente os tecidos econômicos do país, mas particularmente nos territórios mais dependentes das economias de urbanização e de produção no espaço. Nesta fase, a AML como maior sistema urbano português parecia demonstrar alguma resistência, devido à sua diversidade - e como tal, resiliência - de base social, econômica, e no fundo urbana, vendo porém aumentar de forma paulatina os riscos de polarização socioespacial interna. A segunda fase corresponde à implementação de uma acentuada gama de políticas nacionais de austeridade, a partir de 2011: nesta fase é evidente o alargamento dos impactos da crise por sobre os tecidos urbanos da metrópole. Nesses sentidos, e embora não seja possível falar rigorosamente de causalidade, há algumas relações evidentes entre as políticas de austeridade e efeitos sociais, não só sobre as classes mais pobres e mais dependentes das transferências sociais públicas e para-públicas, mas também agora sobre as famílias da classe média, nomeadamente as mais ligadas ao funcionalismo público e às atividades econômicas mais dependentes do Estado e da economia interna - veja-se a correspondência entre queda das viagens nos transportes públicos e incremento das tarifas, ou a redução das transferências sociais em correspondência com o rápido incremento de desemprego e pobreza. 
Finalmente, a AML mostra estar a entrar desde 2013/14 numa terceira fase da crise, perante significativas tendências de emigração que impulsionam a drenagem demográfica não somente das classes mais pobres, mas também de indivíduos jovens e mais qualificados, sendo essa uma nova fase que prefigura sérias mutações de ordem demográfica e uma perda muito preocupante de capital humano.

\section{Mudanças políticas e cívicas na Área Metropolitana de Lisboa}

Esta seção traça um quadro dos padrões de mudança e de reestruturação nas dimensões sociopolíticas e cívicas na metrópole de Lisboa. Enredada entre pressões austeritárias de escala nacional e europeia, e reações de sinal contrário sobretudo nos níveis locais e cívicos, a metrópole apresenta hoje uma paisagem política complexa e mesmo contraditória em determinados campos.

\section{Entre reformas nacionais e respostas locais}

Portugal permanece uma das sociedades institucionalmente mais centralizadas da Europa. É o segundo país europeu não-micro (depois da Grécia) com maior nível de centralização da despesa pública. A proporção de despesa regional e local representa cerca de $15 \%$ de despesa pública em 2011, bem abaixo da média da UE de 25\% (Dexia e CCRE, 2012). Além disso, as regiões, que registram cerca de $4,5 \%$ da despesa pública não são dotadas de governos politicamente autônomos, sendo órgãos desconcentrados do Estado central (Nanetti et al., 2004). Este padrão de centralização é a principal razão da persistente fraqueza nas administrações de âmbito mais local e regional (Seixas e Albet, 2012). Esses parcos recursos encontram-se agora ainda mais diminuídos diante das pressões fiscais induzidas pela crise econômica e, sobretudo, pela redução das transferências nacionais, aplicadas desde 2010. Como resultado, os orçamentos municipais na AML têm tido, com poucas excepções, reduções de $20-30 \%$ desde 2009/2010. ${ }^{11}$

Além dos amplos cortes orçamentais, 0 governo central implementou significativas reformas de âmbitos fiscais e administrativos nos poderes territoriais. Desde logo, através de um gradual e estruturante (com impactos previstos a médio e longo prazo) corte nas receitas fiscais de base local, por sobre a atividade econômica e o próprio setor imobiliário. Em segundo lugar, pela revisão de diversas das principais estruturas de administração territorial (Leis 22/2012 e 75/2013), supostamente delegando competências, mas não sendo essas correspondidas por pacotes financeiros, ao mesmo tempo retirando efetiva capacidade autonômica ao poder local.

Em particular, a Lei 22/2012 relativa à reorganização administrativa territorial assumiu os cortes na despesa pública como leitmotiv para a eliminação de $27 \%$ das 4.260 freguesias (nível de poder mais local) do país. ${ }^{12}$ Essa Lei dava às assembleias municipais 90 dias para elaborar uma proposta de reorganização interna e estabelecer os respetivos critérios. $A$ Associação Nacional de Freguesias contestou a reforma, advogando que a reorganização deveria basear-se em agregações voluntárias e não 
em parâmetros demasiado generalistas (Associação Nacional de Freguesias, 2012). Catorze dos 18 municípios da AML tomaram posição contra a reorganização administrativa, enquanto dois municípios (Sesimbra e Sintra) não apresentaram sequer qualquer proposta nos termos definidos. Como resultado, um grupo de trabalho criado pelo Parlamento nacional impôs a reestruturação administrativa das freguesias em 14 municípios (em dois casos, Sesimbra e Alcochete, 0 antigo modelo foi mantido por cumprir os novos parâmetros exigidos). Diante dessas relevantes reformas, os protestos e as tentativas de resistência, inclusive de base institucional, não surtiram qualquer efeito.

Por seu lado, os municípios de Lisboa e da Amadora escolheram uma abordagem diferenciada, desenvolvendo propostas autônomas de reorganização interna. Na Amadora, a reorganização foi baseada num estudo sociodemográfico e na pretensão de alcançar uma distribuição equitativa dos serviços públicos, bem como num processo consultivo que recebeu cerca de um milhar de contributos (Câmara Municipal de Amadora, 2012). 0 município de Lisboa já trabalhava desde 2009 numa estratégia de reforma administrativa, tendo atendido a uma Lei nacional de base própria, e de acordo com a especificidade concedida pela própria Constituição da República (vejam-se a este propósito os estudos preliminares da reforma de Lisboa-cidade, desenvolvidos por uma equipa científica multidisciplinar, Mateus et al., 2010). A redução do número de freguesias no município de Lisboa (de 53 para 24) foi um dos pilares na direção de uma melhoria global da qualidade de governação urbana. 0 principal objetivo era o de transferir competências de serviço público de proximidade para as juntas de freguesia, anteriormente pouco capacitadas nesse sentido: na gestão e manutenção dos espaços públicos; na emissão de autorizações e licenças urbanísticas de proximidade; no planejamento e gestão de equipamentos e serviços locais; na promoção de programas sociais, culturais e comunitários. A reforma municipal foi submetida a um processo consultivo, que recebeu mais de 7 mil contributos (Mateus et al., 2010; Câmara Municipal de Lisboa, 2011).

A Lei 75/2013, de âmbito nacional, estabelecia quatro objetivos: descentralizar, fortalecer o poder municipal, apoiar as associações voluntárias de municípios, promover a coesão e a competitividade territorial. A Lei previa a delegação de competências do nível nacional para o nível local e intermunicipal, tendo porém relevantes lacunas em campos como os necessários e correspondentes recursos financeiros e fiscais. Da mesma forma, os conselhos metropolitanos e as associações municipais (instituídos em 2008) têm sido mantidos como órgãos meramente coordenadores, sem competências reais, recursos acrescidos ou órgãos eleitos (cf. Crespo e Cabral, 2010). Por conseguinte, não se pode concluir por uma efetiva descentralização, correspondente aos discursos crescentemente desenvolvidos em seu torno - de acordo com Mendes (2015), as reformas em curso a escala nacional configuram-se como um processo de restruturação neoliberal das políticas públicas em favor da competitividade territorial.

Paralelamente ao confronto nacional-local nas reformas administrativas, a aplicação de instrumentos de governação inovadores e capazes de envolver os cidadãos revela por sua vez padrões institucionais de base local de maior resposta aos desafios da crise (e para além dela), evidenciando esforços em construir 
instrumentos de prestação de contas em matéria de despesa local em tempos de contenção. Vários instrumentos têm sido desenvolvidos nos campos da participação, desde a Agenda 21 (implementada em cinco municípios da $A M L$ ), ao orçamento participativo (a ferramenta mais difundida, utilizada em nove dos dezoito municípios), e a vários instrumentos digitais e de consulta na comunicação cidadãos-governo (em Lisboa e Cascais). Contudo, alguns desses instrumentos nem sempre são usados da forma estável e duradoura: por exemplo, a recente história portuguesa dos orçamentos participativos é caracterizada por muita experimentação e alguma instabilidade inerente (Alves e Allegretti, 2012). Alguns municípios cortaram nos valores destinados a estes orçamentos (como Lisboa e Cascais), outros têm usado os orçamentos participativos numa base intermitente (como Odivelas, Oeiras e Sesimbra) e noutros casos o que é apelidado de orçamento participativo resume-se à utilização de instrumentos de consulta (em Alcochete e em Palmela).

\section{Lisboa-Cidade: entre dependências e inovações}

Considerando suas particularidades partidárias e ideológicas, os diferentes municípios da metrópole de Lisboa têm procurado desenvolver novas práticas de tentativa de reação à crise e aos seus efeitos no espaço e sociedade urbanos. Dentre esses, o caso da cidade-centro de Lisboa é particularmente interessante. Desde 2007, um esforço no sentido de inovar tornou-se possível graças a uma conjuntura de maioria e estabilidade política suportada por um governo local de centro-esquerda. Os esforços no sentido de criar reformas sustentáveis e de capacitação política de naturezas territorial e setorial foram moldados em torno de princípios de subsidiariedade, de inovação e de participação. Além da reforma administrativa interna e do fomento de instrumentos de participação acima referidos, duas políticas setoriais podem ser aqui expostas a título exemplar: as políticas de regeneração urbana e as estratégias de promoção e recuperação econômica.

A ênfase na reabilitação de edifícios e na regeneração urbana tem sido compreendida como central numa política urbanística e de planejamento orientada para o fomento de correspondentes investimentos, incluindo ainda incentivos fiscais e financeiros para a reabilitação. ${ }^{13}$ Como resultado de 30 anos de contração demográfica, foi-se acentuando um volume significativo de fogos devolutos (cerca de 50 mil, até recentemente). Desde os anos 1990, o discurso político público vinha enfatizando a necessidade de uma política pública que favorecesse a reabilitação de edifícios, mas poucos resultados tinham sido de fato alcançados. Com o impacto da crise no setor da construção nova, a reabilitação tornou-se uma mais significativa nas estratégias públicas bem como privadas. Além de um estímulo para a recuperação das habitações privadas, o município de Lisboa desenvolveu uma série de medidas de base estratégica para o incentivo à reabilitação por parte dos privados, bem como à requalificação das próprias habitações municipais (cerca de 30.000 fogos) com o objetivo de transferir gradualmente sua propriedade ao longo das próximas décadas (UrbanGuru, 2011). Por seu lado, e seguindo essa tendência, o governo nacional criou recente legislação (Lei 53/2014) para diminuir os requisitos técnicos e com 0 
objetivo de reduzir os custos da reabilitação de construções em cerca de 30\% (Ministério do Ambiente, Ordenamento do Território e Energia, 2014). Contudo, nas políticas de regeneração em curso é ainda evidente uma reprodução de governamentalidades de caráter neoliberal (Tulumello, 2015). As críticas políticas têm assinalado o risco de que apenas os investidores profissionais do imobiliário conseguirão responder a esse desafio, devido à ainda forte crise de crédito que afeta as famílias de classe-média e às suas estratégias no referente à habitação. Por conseguinte, as políticas de reabilitação nos bairros centrais, já bem evidentes e com uma crescente dinâmica, aliadas a outras políticas como as de promoção turística, estão a despoletar tendências de gentrificação (Mendes, 2013) que poderão avolumar-se nos próximos tempos.

Por outro lado, a preocupação com 0 planejamento participado na cidade de Lisboa foi complementada com um programa relativo aos bairros de intervenção prioritária, BIP/ ZIP ou Bairros e Zonas de Intervenção Prioritária. ${ }^{14} 0$ programa BIP/ZIP promove microações de regeneração, financiadas por um processo competitivo anual e implementadas por coligações de atores locais. Embora o esquema seja inovador, a escassez de fundos disponibilizados desde 2011 (1 milhão de euros/ano, cerca de $0,25 \%$ do orçamento municipal) não tem ainda conseguido criar um padrão de influência de forma decisiva na regeneração das diversas áreas degradadas da cidade.

Simultaneamente, várias estratégias de promoção da atividade econômica e de emprego ${ }^{15}$ têm sido desenvolvidas, muito particularmente a partir do desenvolvimento da crise. Esquemas de apoio e de suporte ao empreendedorismo de base urbana têm sido implementados, tais como incubadoras de empresas, incentivos a novos negócios, ${ }^{16}$ áreas criativas e de capital de risco espacial, apoios a iniciativas inovadoras de retalho. 0 desenho de políticas urbanas que permitam o fomento de fluxos internacionais de turismo tem igualmente estado no centro dos esforços do governo municipal. Globalmente, a cidade de Lisboa sofreu o impacto da recessão global do turismo na primeira fase da crise $(-8,9 \%$ de dormidas no período 2007-2009), mas emergiu como um dos principais destinos entre as cidades europeias nos anos seguintes $(+19,4 \%$ dormidas no período 2009-2012) (Câmara Municipal de Lisboa, 2014). Estão em desenvolvimento políticas nestes âmbitos de modo a poder acomodar um maior número de visitantes, tais como áreas de tax-free para hotéis na Baixa da cidade ou investimentos vultuosos na expansão do Terminal de Cruzeiros. Por conseguinte, novas atividades econômicas e serviços bem como novas abordagens multissetoriais à vida citadina vão se instalando na cidade.

\section{Participação cívica durante e para além da crise}

Finalmente, no referente aos padrões evolutivos de base político-eleitoral, as três últimas eleições municipais (2005, 2009 e 2013) mostram uma tendência de crescente insatisfação com a política institucional (Quadro 4). Particularmente nas eleições municipais mais recentes (em 2013), o número de votantes decresceu em cerca de $15 \%$ relativamente às anteriores eleições (em 2009). Nesse contexto, os votos brancos e nulos tiveram um aumento 
significativo em 2013, atingindo 8\% do número total de votos. Pôde ainda ser observado um aumento significativo de candidaturas independentes, um fenômeno quase inexistente até recentemente. Globalmente, os partidos tradicionais mostram perder parcelas significativas de seu eleitorado. A coligação de centro-direita registou uma quebra em 2013, sobretudo relacionada com o sentimento nacional de insatisfação com as políticas de austeridade implementadas pelo governo nacional da mesma cor. Porém, esses votos não se deslocaram para outras forças políticas tradicionais. A única exceção neste panorama mostrou ser o Partido Socialista no município de Lisboa. Aqui, em 2013, o partido do Presidente da Câmara António Costa receberia nova maioria absoluta no executivo municipal, bem como na assembleia municipal, e ainda nos órgãos executivos de 17 das 24 novas freguesias da cidade. Entretanto, a votação de maio de 2014 nas eleições para o Parlamento Europeu confirmaria a tendência para uma redução da participação e uma fragmentação do eleitorado da AML.

A crescente descrença em relação à política tradicional surge em paralelo com a paulatina emergência da participação cívica e de múltiplos movimentos de acção e de protesto. Em 2006, as dinâmicas cívicas na metrópole de Lisboa (organizações cívicas e outras formas de mobilização), embora relativamente fracas, apareciam em expansão (Seixas, 2008). Os inquéritos realizados em 2009 para a reforma administrativa da cidade (Mateus et al., 2010) sublinhavam a emergência de novas culturas sociopolíticas, principalmente nos sectores mais jovens e mais qualificados, por sua vez em expansão nas áreas populacionais mais densas. Em tempos de crise e de política de austeridade, alguns sinais de participação cívica renovada tornam-se assim evidentes a partir de duas perspetivas.

Quadro 4 - Eleições autárquicas na AML, 2009-2013

\begin{tabular}{|c|c|c|c|c|c|c|}
\hline & Distrito & 2005 & 2009 & 2013 & $\begin{array}{c}\text { Variação } \\
\text { 2005-2009 }\end{array}$ & $\begin{array}{c}\text { Variação } \\
\text { 2009-2013 }\end{array}$ \\
\hline Votantes & $\begin{array}{l}\text { Lisboa } \\
\text { Setúbal }\end{array}$ & $\begin{array}{l}53,1 \% \\
50,2 \%\end{array}$ & $\begin{array}{l}52,1 \% \\
49,6 \%\end{array}$ & $\begin{array}{l}44,5 \% \\
41,7 \%\end{array}$ & $\begin{array}{l}-1,9 \% \\
-1,2 \%\end{array}$ & $\begin{array}{l}-14,6 \% \\
-15,9 \%\end{array}$ \\
\hline $\begin{array}{l}\text { Votos para os partidos } \\
\text { tradicionais }\end{array}$ & $\begin{array}{l}\text { Lisboa } \\
\text { Setúbal }\end{array}$ & $\begin{array}{l}90,8 \% \\
94,0 \%\end{array}$ & $\begin{array}{l}92,2 \% \\
93,7 \%\end{array}$ & $\begin{array}{l}80,9 \% \\
86,4 \%\end{array}$ & $\begin{array}{r}1,5 \% \\
-0,3 \%\end{array}$ & $\begin{array}{r}-12,2 \% \\
-7,8 \%\end{array}$ \\
\hline $\begin{array}{l}\text { Votos para os partidos } \\
\text { independentes }\end{array}$ & $\begin{array}{l}\text { Lisboa } \\
\text { Setúbal }\end{array}$ & $\begin{array}{l}2,8 \% \\
0,1 \%\end{array}$ & $\begin{array}{l}3,7 \% \\
1,2 \%\end{array}$ & $\begin{array}{l}7,4 \% \\
2,0 \%\end{array}$ & $\begin{array}{r}32,1 \% \\
1.100,0 \%\end{array}$ & $\begin{array}{r}100,0 \% \\
66,7 \%\end{array}$ \\
\hline Votos brancos ou nulos & $\begin{array}{l}\text { Lisboa } \\
\text { Setúbal }\end{array}$ & $\begin{array}{l}5,2 \% \\
4,9 \%\end{array}$ & $\begin{array}{l}3,0 \% \\
3,2 \%\end{array}$ & $\begin{array}{l}8,2 \% \\
8,2 \%\end{array}$ & $\begin{array}{l}-42,3 \% \\
-34,7 \%\end{array}$ & $\begin{array}{l}173,3 \% \\
156,3 \%\end{array}$ \\
\hline
\end{tabular}

Elaborado pelos autores. Dados: Direção Geral da Administração Interna (http://www.dgai.mai.gov.t/?area=103\&mid=001\&s $i d=003)$. 
Por um lado, as dinâmicas de movimentos de protesto, sobretudo contra as medidas de austeridade e que têm sido organizados desde 2010 por organizações não partidárias. Esse ciclo de protesto parece caracterizar-se por três dimensões. Em primeiro lugar, é protagonizado por plataformas de movimentos sociais e novas organizações em articulação com as organizações sindicais marcando eventos de protesto, e produzindo leituras autónomas sobre as razões e as soluções para a crise - vejam-se os relatórios da Iniciativa para uma Auditoria Cidadã sobre a questão dívi$\mathrm{da},{ }^{17}$ ou programa elaborado pelo Congresso Democrático das Alternativas ${ }^{18}$. Em segundo lugar, há traços de influência e articulação internacional nos protestos - marcação de manifestações para datas internacionalmente acordadas, bem como encenações dos protestos que reproduzem modelos de outros países, como a ocupação de espaços público e assembleias populares dos Indignados/ Occupy - embora, significativamente, as reivindicações tenham sempre por referência o espaço nacional e seus responsáveis políticos (Baumgarten, 2013). Em terceiro lugar, os protestos públicos mais mobilizadores tendem a organizar-se em torno das questões laborais: o primeiro decorre ainda antes do programa de ajustamento da Troika, em março 2011, sob o mote da "Geração à rasca", denunciando o desemprego e a crescente precarização dos jovens. Realizam-se cinco greves gerais entre 2010 e 2013, três das quais convocadas por ambas as centrais sindicais portuguesas, e em setembro de 2012, uma proposta do Governo de alteração nas contribuições para o regime de pensões, que favorecia os empregadores e prejudicava os trabalhadores, terá levado mais de 1 milhão de pessoas à rua (Baumgarten, 2013; Estanque, 2014). Embora esses protestos não sejam quantitativamente comparáveis aos protestos de outras sociedades europeias como na Espanha ou na Grécia, foram contudo os maiores protestos sociais na história do Portugal democrático. Accornero e Ramos Pinto (2015) analisam esse ciclo de protestos entre 2010-2013, sublinhando que esse se caracteriza por uma conexão crítica entre "novos-novos movimentos" - uma definição relativa à organização a partir da base e pelo uso das TICs como instrumento de organização - e as forças tradicionais como os partidos de esquerda e os sindicatos.

Por outro lado, têm nascido e multiplicado múltiplos movimentos urbanos de base criativa e alternativa. Dois exemplos, entre muitos outros e nas mais variadas dimensões: a associação Habita ${ }^{19}$ é a primeira rede a fornecer apoio e informação aos moradores sobre despejos sem realojamento dos bairros de lata ou contra os aumentos de renda nas habitações camarárias. A Plataforma Gueto ${ }^{20}$ promove a inclusão dos imigrantes, procede à análise da legislação e das políticas e fornece assistência às famílias vítimas de violência policial em várias áreas periféricas de Lisboa. Surgiram ainda alguns grupos de ativistas locais que recriam modelos próximos dos centros sociais italianos, criando espaços de debate e oficinas de projetos em torno de modelos alternativos de vivência urbana - apoio à mobilidade suave, mercados de troca direta, cantinas comunitárias - como o espaço RDA 69 ou edifício ocupado São Lázaro 94, entretanto despejado pela polícia em 2012 (Baumgarten, 2013). 


\section{Conclusões}

Este artigo propôs-se uma análise combinada de três vertentes, nomeadamente (1) a evolução geográfica e sociopolítica na AML ao longo do desenvolvimento da crise econômica, (2) as medidas de austeridade prosseguidas em Portugal e seus impactos, e ainda (3) a conjugação dessas com as reações sociopolíticas de âmbito mais local.

A análise conjugada dos dois primeiros eixos permite propor uma combinação relacional entre o que se chamou de três fases das políticas anticrise (cf. seção "Questões de contexto: a agenda da austeridade e seus impactos em Portugal) com as três ordens de crise sucessivas (cf. seção "Área Metropolitana de Lisboa: a crise em movimento"). Durante o período de estímulo econômico e primeira fase da austeridade (grosso modo até início do ano de 2011) os impactos da crise parecem limitados a alguns setores sociais e a muito específicas áreas urbanas, com uma geral capacidade de resiliência do tecido socioterritorial. Porém, é com o advento da austeridade em grande escala, após o início do programa de resgate externo, que os efeitos da crise se generalizam na AML: efeitos que continuam após o fim do programa de resgate, agora com uma germinal crise demográfica que, potencialmente, terá relevantes efeitos de longo prazo. Assim, as correlações entre as medidas de austeridade e os impactos sociais da crise mostram ser evidentes, defendendo-se desde logo a realização de análises de maior profundidade no sentido de se discernir com mais precisão e posicionamento, os elementos e as relações mais específicas de causalidade, bem como um maior detalhe nos respectivos impactos socioespaciais.
É tendo como pano de fundo este quadro dinâmico que podemos, agora, adicionar à discussão o terceiro eixo da análise, que evidenciou um quadro sociopolítico consideravelmente complexo e composto por estratégias e dinâmicas com efeitos contraditórios e mesmo conflitantes. Nessa área podemos identificar duas tendências principais de reestruturação sociopolítica na evolução da AML: as políticas nacionais, de assumida primordialidade financeira, e as políticas mais locais e de cariz mais social e ambiental, de primordialidade territorial.

Denota-se um evidente - e crescente confronto entre as políticas top-down de austeridade e de cortes públicos, e as reacções e dinâmicas sociopolíticas bottom-up, desenhando-se um quadro crescentemente complexo de intersecções de base multi-escalar, como exemplificado pelos processos de reorganização administrativa à escala local. Embora a respectiva Lei nacional tenha visado sobretudo uma redução de despesa pública, em lugar de uma efetiva descentralização, alguns municípios tomaram uma postura mais pró-ativa e de reforço da governação pública de proximidade nas suas propostas de reestruturação político-administrativa. As visões de base histórica - e revigoradas diante da crise - para uma cultura de "localismo austeritário" em Portugal, encontram-se atualmente em contestação perante dinâmicas de maior capacitação e de resistência de base local. A somar a essas tendências, assiste-se a uma evolução do ativismo social e da participação cívica, o que coloca ainda maiores pressões sobre as abordagens institucionais top-down.

De forma global, o fomento de uma série de dimensões de base conflituante encontra-se 
a reestruturar as dinâmicas sociopolíticas na Área Metropolitana de Lisboa, tanto diante dos âmbitos da crise, como mesmo para além dessa. É assim essencial perceber e interpretar quais das pressões serão mais sustentadas e mais fortes, colocando adequadas perguntas e hipóteses. Será que a ação de determinados governos locais, bem como a dinâmica de determinadas comunidades, se encontra a construir distintas e crescentemente sólidas narrativas sociopolíticas, sendo capazes de ultrapassar culturas de natureza secular, rendidas às pressões financeiras? Ou será que, por outro lado, a crescente fratalização socioespacial potenciará uma respectiva fragmentação sociopolítica? Será ainda, por outro lado, que a exigência do fomento de novos padrões de equidade (e de qualidade) urbana surge justificada por agentes reativos à crise; ou antes pela própria crise e seus agentes, num processo aparentemente paradoxal? E finalmente, que princípios e que objetivos de base política deverão ser desenvolvidos - ou reforçados - nos espaços da vida urbana?

Não obstante essas análises terem sido realizadas com base na metrópole de Lisboa, diversas análises recentes e de ordem paralela nas metrópoles do sul da Europa sugerem uma considerável generalização tanto dos efeitos como das interpretações de base crítica, no que concerne à evolução contemporânea dos territórios e da sociopolítica urbana diante da crise europeia (Seixas e Albet, 2012; Knieling e Othengrafen, 2016). Nesse âmbito, a Europa Meridional pode ser vista como um território bastante privilegiado para a análise e interpretação das tendências de governação urbana e territorial; e mesmo da evolução da própria geopolítica em âmbitos mais globais (Nel.lo,
2001; Chorianopoulos, 2002, Leontidou, 2010; Tulumello, 2013).

Em conclusão, estas análises poderão permitir um esboço preliminar de determinadas novas questões para uma agenda de pesquisa. Tal agenda deve conter tanto uma perspectiva de trabalho teórico e conceitual, como de enfoque em questões práticas e de real qualificação de estruturas institucionais bem como de políticas públicas, e notavelmente para as cidades e metrópoles que mais enfrentam a crise. Observando quer os impactos, quer as reações da e perante a crise nos diversos tecidos urbanos, cremos que tal agenda deve explorar, desde logo, a (re)produção da crise e seus padrões socioespaciais, em diferentes épocas, agentes e contextos. As dimensões da política e das políticas, e como tal as paisagens e as dinâmicas político-institucionais, devem ser abordadas através da exploração de como diferentes culturas políticas e distintos regimes urbanos se vão transformando e reestruturando nas suas relações verticais e horizontais, diante de princípios essênciais de governo territorial, tais como os padrões de subsidiariedade, de autonomia e de capacitação efetiva de governação.

Neste sentido, um enfoque em torno das reações à crise desenvolvidas nos níveis mais locais, mas também nos níveis dos sistemas urbanos/metropolitanos será chave para 0 questionamento sobre se os regimes urbanos se encontrarão a desenvolver algum tipo de adaptabilidade ou de resiliência perante choques externos, ou se estarão mesmo a desenvolver mutações de ordem mais estruturante e que tenham a capacidade de questionar stata quo e desenvolver ativações de diferente ordem. Um apelo é assim feito, tanto à academia 
como a outras ordens profissionais e de ativistas, no sentido do desenvolvimento de redes capazes de conectar e incentivar territórios e conhecimentos, reestruturando os próprios estudos urbanos a partir destas - e decerto de outras - perspectivas.

\section{João Seixas}

Universidade Nova de Lisboa, Centro Interdisciplinar de Ciências Sociais. Lisboa, Portugal. jcfseixas@gmail.com

\section{Simone Tulumello}

Universidade de Lisboa, Instituto de Ciências Sociais. Lisboa, Portugal. simone.tulumello@ics.ulisboa.pt

\section{Susana Corvelo}

Instituto Universitário de Lisboa, Centro de Estudos sobre a Mudança Socioeconómica e o Território. Lisboa, Portugal.

sscorvelo@gmail.com

\section{Ana Drago}

Instituto Universitário de Lisboa, Centro de Estudos sobre a Mudança Socioeconómica e o Território. Lisboa, Portugal.

drago.ana@gmail.com

\section{Notas}

(1) Sendo a Área Metropolitana de Lisboa o objeto deste estudo, algumas seções do texto focamse no município central (o concelho de Lisboa), como centro da região metropolitana e com determinadas características de natureza sociopolítica mais específicas (cf. seção "Lisboacidade: entre dependências e inovações").

(2) De acordo com Pedroso (2014), os governos portugueses que se sucederam desde 2008 têm adaptado as políticas anticrise ao mainstream das políticas europeias: suporte às instituições bancárias (março a dezembro 2008); políticas de estímulo à economia (dezembro 2008 a fevereiro 2010); consolidação orçamental e austeridade (fevereiro 2010 até agora). A distinção entre duas fases da austeridade, respectivamente antes e depois o resgate internacional, é nossa - debater-se-ia ao longo do artigo a sua significância.

(3) Lei $64-\mathrm{A} / 2008$.

(4) Elaborado pelos autores. Dados: Estatísticas do Banco de Portugal (www.bportugal.pt/ estatisticasweb). 
(5) Elaborado pelos autores. Dados: Pordata (www.pordata.pt/).

(6) Exceto quando especificado, todos os dados provêm do Instituto Nacional de Estatística (www. ine.pt).

(7) O ISDR é um estudo estatístico anual que considera as 25 regiões portuguesas. Com base numa matriz de 65 indicadores estatísticos, distribuídos por três componentes - competitividade, coesão e qualidade ambiental - e posteriormente agregados por média não ponderada, obtêm-se quatro indicadores compósitos - competitividade, coesão, qualidade ambiental e índice global de desenvolvimento regional. Os quatro indicadores compósitos são apresentados por referência ao contexto nacional (Portugal $=100$ ), a recolha dos dados é indireta e as variáveis que os integram provêm de procedimentos administrativos e operações estatísticas desenvolvidas no contexto do Sistema Estatístico Nacional. Mais em: https://www.ine.pt/ xportal/xmain?xpid=INE\&xpgid=ine_destaques\&DESTAQUESdest_boui=215612718\&DESTAQU ESmodo=2).

(8) Formação Bruta de Capital Fixo é um indicador macroeconômico usado para medir o investimento físico de uma economia.

(9) 2009 - 113,168; 2010 - 129,206; 2011 - 129,540; 2012 - 156,420; 2013 - 167,413; 2014 - 152,269 (Valor médio anual) (IEFP, vários anos).

(10) Para mais informação sobre conceitos, indicadores e fórmulas de cálculo, consultar o Inquérito às Condições de Vida e Rendimento em https://www.ine.pt/xportal/xmain?xpid=INE\&xpgid=ine_ destaques\&DESTAQUESdest_boui=223346238\&DESTAQUESmodo=2.

(11) Dados elaborados pelos autores a partir da análise dos orçamentos municipais, 2009-2014.

(12) Os dados que se seguem resultam da análise dos documentos elaborados pelo Grupo de Trabalho criado pelo Parlamento (UTRAT, 2012), a Associação Nacional de Freguesias (2012) e os websites dos municípios que submeteram propostas ou tomaram posição contra a reorganização.

(13) Veja-se em http://www.cm-lisboa.pt/viver/urbanismo/reabilitacao-urbana/incentivos-fiscais-eoperacionalizacao.

(14) Ver http://habitacao.cm-lisboa.pt/index.htm?no=2730001.

(15) Ver http://www.cm-lisboa.pt/investir.

(16) Ver http://www.cm-lisboa.pt/investir/empreendedorismo.

(17) Ver http://auditoriacidada.info/.

(18) Ver http://www.congressoalternativas.org/.

(19) Ver www.habita.info/.

(20) Ver http://plataformagueto.wordpress.com/. 


\section{Referências}

ABREU, A.; MENDES, H.; RODRIGUES, J.; GUSMÃO, J. G.; SERRA, N.; ALVES, P. D. e MAMEDE, R. P. (2013). A crise, a troika e as alternativas urgentes. Lisboa, Tinta da China.

ACCORNERO, G. e RAMOS PINTO, P. (2015). Mild mannered'? Protest and mobilisation in Portugal under austerity, 2010-2013. West European Politics, v. 38, n. 3, pp. 491-515.

ALVES, M. L. e ALLEGRETTI, G. (2012). (In)stability, a key element to understand participatory budgeting: discussing Portuguese cases. Journal of Public Deliberation, v. 8, n. 2.

ALVES, S. (2014). Welfare state changes and outcomes - The cases of Portugal and Denmark from a comparative perspective. Social Policy and Administration, v. 49, n. 1, pp. 1-23.

AMTL (Autoridade Metropolitana de Transportes de Lisboa) (2013). Procura de transportes públicos na $A M L$ - 2013. Disponível em: www.amtl.pt?cr=9598. Acesso em: 15 mar 2015.

(2014). Procura de transportes públicos na AML - 2014. Disponível em: www.amtl.pt?cr=9599. Acesso em: 15 mar 2015.

ASSOCIAÇÃO NACIONAL DE FREGUESIAS (2012). Proposta de Lei no 44/XII/1. a (GOV) - Aprova o regime jurídico da reorganização administrativa territorial autárquica. Parecer. Disponível em: www. anafre.pt/freguesias-associadas/reorganizacao-administrativa/parecer-anafre. Acesso em: 15 mar 2015.

BAPTISTA, I. (2013). The travels of critiques of neoliberalism: urban experiences from the 'Borderlands'. Urban Geography, v. 34, n. 5, pp. 590-611.

BAUMGARTEN, B. (2013). Geração à Rasca and beyond: mobilizations in Portugal after 12 march 2011. Current Sociology, v. 61, n. 4, pp. 457-473.

BLYTH, M. (2013). Austerity. The history of a dangerous idea. Nova York, Oxford University Press.

BRENNER, N. (2004). New state spaces. Urban governance and the rescaling of statehood. Oxford, Oxford University Press.

BRENNER, N.; PECK, J. e THEODORE, N. (2010). After neoliberalization? Globalizations, v. 7, n. 3, pp. 327-345.

CÂMARA MUNICIPAL DE AMADORA (2012). Reorganização Administrativa Territorial do Município da Amadora. Disponível em: http://ra.cm-amadora.pt/PageGen.aspx?WMCM_Paginald=29188. Acesso em: 15 mar 2015.

CÂMARA MUNICIPAL DE LISBOA (2011). Reforma Administrativa da Cidade de Lisboa. Relatório da Discussao Pública. Disponível em: http://www.youblisher.com/p/120029-Relatorio-da-ConsultaPublica-da-Reforma-Administrativa-da-Cidade/. Acesso em: 15 mar 2015.

(2014). A Economia de Lisboa em números. Turismo. Disponível em: www.cm-lisboa.pt/ fileadmin/INVESTIR/logos_areas/economia_cidade_imagens/Turismo_012014.xls. Acesso em: 15 mar 2015

CCDR-LVT (Comissão de Coordenação e Desenvolvimento Regional de Lisboa e Vale do Tejo) (2013). Plano de Ação Regional de Lisboa 2014-2020 (Diagnóstico Prospetivo). Disponível em: www. ccdr-lvt.pt/pt/documentacao-ja-produzida/7906.htm. Acesso em: 15 mar 2015. 
CEC (Commission of the European Communities) (2008). Communication from the Commission to the European Council. A European economic recovery plan. COM (2008) 800 final. Disponível em: http://ec.europa.eu/economy_finance/publications/publication13504_en.pdf. Acesso em: 15 mar 2015.

(2011). Cities of tomorrow. Challenges, visions, ways forward. Disponível em: http://ec.europa. eu/regional_policy/sources/docgener/studies/pdf/citiesoftomorrow/citiesoftomorrow_final. pdf. Acesso em: 15 mar 2015.

CHORIANOPOULOS, I. (2002). Urban restructuring and governance: North-South differences in Europe and the EU urban initiatives. Urban Studies, v. 39, n. 4, pp. 705-726.

COtella, G.; Othengrafen, F.; PAPAiOANnOU, A. e TUlUMELlO, S. (2016). "Socio-political and socio-spatial implications of the crisis in European cities". In: KNIELING, J. e OTHENGRAFEN, F. (orgs.). Cities in crisis. Reflections on the socio-spatial impacts of the economic crisis and the strategies and approaches applied by Southern European cities. Londres, Routledge, pp. 27-47.

CRESPO, J. L. e CABRAL, J. (2010). The institutional dimension to urban governance and territorial management in the Lisbon Metropolitan Area. Análise Social, n. 197, pp. 639-662.

DEXIA e CCRE (Conseil de Communes et Régions d'Europe) (2012). Subnational Public Finance in the European Union. Summer 2012. Disponível em: www.ccre.org/docs/Note_CCRE_Dexia_EN.pdf. Acesso em: 15 mar 2015.

ESTANQUE, E. (2014). Rebeliões de classe média? Precariedade e movimentos sociais em Portugal e no Brasil. Revista Crítica de Ciências Sociais, n. 103, pp. 53-80.

FERNANDES, J. R. e CHAMUSCA P. (2014). Urban policies, planning and retail resilience. Cities, n. 36, pp. 170-177.

FERRÃO, J. (2013). "Território". In: CARDOSO, J. L.; MAGALHÃES, P. e MACHADO PAIS, J. (orgs.). Portugal social de A a Z. Temas em Aberto. Paço de Arcos, Expresso, pp. 244-257.

HADJIMICHALIS, C. (2011). Uneven geographical development and socio-spatial justice and solidarity: European regions after the 2009 financial crisis. European Urban and Regional Studies, v. 18, n. 3, pp. 254-274.

HARVEY, D. (2005). A brief history of neoliberalism. Oxford, Oxford University Press.

IEFP (Instituto de Emprego e Formação Profissional) (vários anos). Informação Mensal do Mercado de Emprego. Disponível em: https://www.iefp.pt/estatisticas. Acesso em: 15 mar 2015.

INE (Instituto Nacional de Estatística) (2012). Inquérito às Condições de Vida e Rendimento. Destaque de 15 de julho de 2013. Disponível em: http://www.ine.pt/xportal/xmain?xpid=INE\&xpgid=ine destaques\&DESTAQUESdest_boui=156015568\&DESTAQUESmodo=2. Acesso em: 15 mar 2015.

(2014a). Anuário Estatístico de Portugal. Destaque de 1ㅇ de dezembro de 2014. Disponível em: http://www.ine.pt/xportal/xmain?xpid=INE\&xpgid=ine_destaques\&DESTAQUESdest_ boui=223549784\&DESTAQUESmodo=2. Acesso em: 15 mar 2015.

(2014b).Inquéritoàs condições devidaerendimento. Destaquede30dejaneirode2015. Disponível em: http://www.ine.pt/xportal/xmain?xpid=INE\&xpgid=ine_destaques\&DESTAQUESdest_ boui=223346238\&DESTAQUESmodo=2. Acesso em: 15 mar 2015. 
KNIELING, J. e OTHENGRAFEN, F. (org.) (2016). Cities in crisis. Reflections on the socio-spatial impacts of the economic crisis and the strategies and approaches applied by Southern European cities. Londres, Routledge.

KRUGMAN, P. (2012). End this depression now! Nova York, W.W. Norton \& Company.

LEONTIDOU, L. (2010). Urban social movements in 'weak' civil societies: The right to the city and cosmopolitan activism in Southern Europe. Urban Studies, v. 47, n. 6, pp. 1179-1203.

MATEUS, A.; SEIXAS, J. e VITORINO, N. (orgs.) (2010). Qualidade de vida e governo da cidade. Bases para um novo modelo de governação da cidade de Lisboa. Lisboa, ISEG.

MENDES, L. (2013). Public policies on urban rehabilitation and their effects on gentrification in Lisbon. AGIR - Revista Interdisciplinar de Ciências Sociais e Humanas, v. 1, n. 5, pp. 200-218.

(2015). Globalização e novas condições para o governo neoliberal do território: Preludio à nova reforma da administração do poder local português. Movimentos Sociais e Dinâmicas Espaciais, v. 4, n. 1, pp. 188-206.

MINISTÉRIO DO AMBIENTE, ORDENAMENTO DO TERRITORIO E ENERGIA (2014). Regime Excecional para a Reabilitação Urbana (RERU). 24 de fevereiro. Disponível em: www.portugal.gov.pt/ media/1351721/20140224\%20regime\%20excecional\%20recuperacao\%20urbana.pdf. Acesso em: 15 mar 2015.

NANETTI, R. Y.; RATO, H. e RODRIGUES, M. (2004). Institutional capacity and reluctant decentralization in Portugal: The Lisbon and Tagus Valley region. Regional \& Federal Studies, v. 14, n. 3, pp. 405-429.

NEL.LO, O. (2001). Ciutat de Ciutats. Barcelona, Editorial Empúries.

OBSERVATÓRIO DA EMIGRAÇÃO (2014). Emigração Portuguesa. Relatório Estatístico 2014. Disponível em: www.observatorioemigracao.secomunidades.pt/np4/?newsld=3924\&fileName=OEm_ EmigracaoPortuguesa2014_RelatorioEst.pdf. Acesso em: 15 mar 2015.

OOSTERLYNCK, S. e GONZÁLEZ, S. (2013). 'Don't waste a crisis': Opening up the city yet again for neoliberal experimentation. International Journal of Urban and Regional Research, v. 37, n. 3, pp. 1075-1082.

PECK, J. (2013). Explaining (with) neoliberalism. Territory, Politics, Governance, v. 1, n. 2, pp. 132-157.

PECK, J.; THEODORE, N. e BRENNER, N. (2013). Neoliberal urbanism redux? International Journal of Urban and Regional Research, v. 37, n. 3, pp. 1091-1099.

PEDROSO, P. (2014). Portugal and the global crisis. The impact of austerity on the economy, the social model and the performance of the state. Lisboa, Friederich Ebert Stiftung.

REIS, J. e RODRIGUES, J. (orgs.) (2011). Portugal e a Europa em crise. Para acabar com a economia de austeridade. Lisboa, Actual.

RODRIGUES, J. e TELES, N. (2011). "Portugal e o neoliberalismo como intervencionismo de mercado". In: REIS, J. e RODRIGUES, J. (orgs.). Portugal e a Europa em crise. Para acabar com a economia de austeridade. Lisboa, Actual, pp. 34-46.

ROITMAN, J. (2014). Anti-crisis. Durham, Duke University Press.

SAGER, T. (2011). Neo-liberal urban planning policies: A literature survey 1990-2010. Progress in Planning, v. 76, n. 4, pp. 147-199. 
SANTOS, A. C. (2013). "Temos vivido acima das nossas possibilidades?" In: SOEIRO, J.; CARDINA, M. e SERRA, N. (orgs.). Não acredite em tudo o que pensa. Mitos do senso comum na era da austeridade. Lisboa, Tinta da China, pp. 17-30.

SANTOS, A. C. e COSTA, V. (2013). Regular o consumidor? Novas tendências de política no sector financeiro. Análise Social, n. 209, pp. 756-791.

SCHWARTZ, H. (2012). Housing, the welfare state, and the global financial crisis: What is the connection? Politics \& Society, v. 40, n. 1, pp. 35-58.

SEIXAS, J. (2008). "Estruturas e dinâmicas do capital sociocultural em Lisboa". In: CABRAL, M. V.; SILVA, F. C. e SARAIVA, T. (orgs.). Cidade \& cidadania-Governança urbana e participação cidadã. Lisboa, Imprensa de Ciências Sociais.

(2013). A cidade na encruzilhada. Repensar a cidade e a sua política. Porto, Edições Afrontamento

SEIXAS, J. e ALBET, A. (orgs.) (2012). Urban governance in Southern Europe. Farnham, Ashgate.

TULUMELLO, S. (2013). Panopticon sud-europeo: (Video)sorveglianza, spazio pubblico e politiche urbane. Archivio di Studi Urbani e Regionali, n. 107, pp. 30-51.

(2015). Reconsidering neoliberal urban planning in times of crisis: Urban regeneration policy in a "dense" space in Lisbon. Urban Geography, Doi: 10.1080/02723638.2015.1056605.

URBANGURU (2011). Programa de Intervenção Estratégica no Património Habitacional Municipal e nos Devolutos Municipais. Relatório final. Disponível em: http://habitacao.cm-lisboa.pt/docume ntos/1323729521D4qVS7sI3Eu87LY5.pdf. Acesso em: 15 mar 2015.

UTRAT (Unidade Técnica para a Reorganização Administrativa do Territorio) (2012). Proposta Concreta de Reorganização Administrativa do Territorio [vários documentos por cada municipalidade portuguesa]. Disponíveis em: http://app.parlamento.pt/utrat/index.html. Acesso em: 15 mar 2015.

WACQUANT, L. (2012). Three steps to a historical anthropology of actually existing neoliberalism. Social Anthropology, v. 20, n. 1, pp. 66-79.

WERNER, R. A. (2013). Crises, the spatial distribution of economic activity, and the geography of banking. Environment and Planning A, v. 45, n. 12, pp. 2789-2796.

Texto recebido em 2/abr/2015

Texto aprovado em 11/ago/2015 
